\title{
Investigation of froth flotation for beneficiation of printed circuit board comminution fines
}

\author{
I.O. Ogunniyi ${ }^{*}$, M.K.G. Vermaak \\ Department of Materials Science and Metallurgical Engineering, University of Pretoria, Pretoria 0002, South Africa
}

\section{A R T I C L E I N F O}

\section{Article history:}

Received 28 May 2008

Accepted 27 October 2008

Available online $\mathrm{xxxx}$

\section{Keywords:}

Recycling

Froth flotation

Printed circuit boards

\begin{abstract}
A B S T R A C T
Froth flotation for beneficiation of printed circuit board comminution fines was investigated in this work, via reverse flotation under a scheme described as natural hydrophobic response. With no reagents, the scheme employed variation of kinetic parameters of airflow rate and impeller speed to optimize metallic enrichment of the sink. The impeller energy and aeration rate required to keep the pulp in suspension and avoid excessive turbulence were found to be much lower compared with conventional mineral flotation. The natural hydrophobic response was found to exist, and stable froth was observed even without the use of any frother. It was submitted that the dynamic froth stability observed is due to fine particle stabilization. Mass pulls obtained were high and cumulative mass pull under the varying kinetic regimes were found to fit very well to the general first order kinetics. The extents of fit, the sink enrichment and the recovery in respect of metallic values were assessed to evaluate the beneficiation performance. Many of the metallic elements were found to concentrate into the sink, while some prefer the froth phase. Notably, gold and palladium were among the best recovered to the sink; with about $64 \%$ recovery at enrichment ratio of $3.1(676 \mathrm{ppm}$ actual assay) for Au. The flotation scheme proved effective for PCB comminution fines, and performance improvement also looks very feasible.
\end{abstract}

(c) 2008 Elsevier Ltd. All rights reserved.

\section{Introduction}

End-of-life printed circuit board (eol PCB) assays far above many base and precious metals natural deposits (Table 1), and is therefore recognized as a respectable poly-metallic secondary resource. Sustainability in material use in the face of depleting natural reserves is another driver in this regard. Physical (or mechanical) processing is recognized as the most environmentally friendly alternative for resource recovery from eol PCBs (Goosey and Kellner, 2002). A major challenge to the physical processing alternative is the poor recovery of the base and precious metal values deported to the $-75 \mu \mathrm{m}$ fine fraction generated during the comminution operation (Goosey and Kellner, 2002; Zhao et al., 2004; Ogunniyi and Vermaak, 2007). Assessing this as an applied minerals processing problem, froth flotation has been advanced as a promising beneficiation technique for this fine fraction (Ogunniyi and Vermaak, in press). However, PCB comminution fines (CF) differs from conventional minerals, being much more heterogeneous in make up, with a complete range of plastic, ceramic, metallic and alloy particles expected in its constituents. A compilation of representative $\mathrm{PCB}$ compositions as in Table 1 gives an indication of the variety of particles that can be expected in the fines. Glass

\footnotetext{
* Corresponding author.

E-mail addresses: mrolatunji@yahoo.com, mrolatunji@tuks.co.za (I.O. Ogunniyi).
}

fiber and plastic thermosets, being brittle, report substantially to this fine fraction. With about 10-15 different base and precious metals as possible target values, this sample will result in a relatively complex flotation system.

A probable starting scheme advanced for this application was described as natural hydrophobic response (Ogunniyi and Vermaak, in press). The fine particles being so diverse, some are expected to exhibit natural hydrophobicity (e.g. particles from comminution of plastic components). Such particles are expected to float under their natural hydrophobicity, thus making it possible to achieve an initial bulk metallic enrichment of the sink before attempting any surface conditioning for further selective floats. This implies a reverse flotation in respect of the metallic values. Exploiting natural hydrophobicity, as well as reverse flotation is quite common in coal and iron ore flotation, respectively (Arnold and Aplan, 1989; Araujo et al., 2005), while some application of flotation has also been reported in waste processing (Saitoh et al., 1976; Shent et al., 1999; Dodbiba et al., 2002; Alter, 2005).

However, with this unconventional sample, the usual range of kinetic operating parameters in conventional minerals flotation may not be invoked. Moreover, with no reagent collector to control, appropriate hydrodynamics condition will be critical to the flotation performance of the proposed scheme. Seeking appropriate kinetics to achieve efficient particle-bubble collision for hydrophobic attachment can be faced with the challenge of selectivity 
Table 1

Representative material compositions of PCBs in weight percent.

\begin{tabular}{|c|c|c|c|c|c|c|c|c|}
\hline Materials & & $\%^{\mathrm{a}}$ & $\%$ & $\%^{\mathrm{c}, \mathrm{d}}$ & $\%{ }^{\mathrm{e}}$ & $\%{ }^{\mathrm{f}}$ & $\%^{\mathrm{g}}$ & $\%^{\mathrm{h}}$ \\
\hline \multirow[t]{12}{*}{ Metals (max. 40\%) } & $\mathrm{Cu}$ & 20 & 26.8 & 10 & 15.6 & 22 & 17.85 & 23.47 \\
\hline & $\mathrm{Al}$ & 2 & 4.7 & 7 & - & - & 4.78 & 1.33 \\
\hline & $\mathrm{Pb}$ & 2 & - & 1.2 & 1.35 & 1.55 & 4.19 & 0.99 \\
\hline & $\mathrm{Zn}$ & 1 & 1.5 & 1.6 & 0.16 & - & 2.17 & 1.51 \\
\hline & $\mathrm{Ni}$ & 2 & 0.47 & 0.85 & 0.28 & 0.32 & 1.63 & 2.35 \\
\hline & $\mathrm{Fe}$ & 8 & 5.3 & - & 1.4 & 3.6 & 2.0 & 1.22 \\
\hline & Sn & 4 & 1.0 & - & 3.24 & 2.6 & 5.28 & 1.54 \\
\hline & $\mathrm{Sb}$ & 0.4 & 0.06 & - & - & - & - & - \\
\hline & $\mathrm{Au} / \mathrm{ppm}$ & 1000 & 80 & 280 & 420 & 350 & 350 & 570 \\
\hline & $\mathrm{Pt} / \mathrm{ppm}$ & - & - & - & - & - & 4.6 & 30 \\
\hline & $\mathrm{Ag} / \mathrm{ppm}$ & 2000 & 3300 & 110 & 1240 & - & 1300 & 3301 \\
\hline & $\mathrm{Pd} / \mathrm{ppm}$ & 50 & - & - & 10 & - & 250 & 294 \\
\hline \multirow[t]{4}{*}{ Ceramic (max. $30 \%)^{a}$} & $\mathrm{SiO}_{2}$ & 15 & 15 & - & 41.86 & 30 & - & - \\
\hline & $\mathrm{Al}_{2} \mathrm{O}_{3}$ & 6 & - & - & 6.97 & - & & \\
\hline & Alkaline and alkaline earth oxides & 6 & - & - & $\mathrm{CaO} 9.95 \mathrm{MgO} 0.48$ & - & & \\
\hline & Titanates, mica, etc. & 3 & - & - & - & - & - & -- \\
\hline \multirow[t]{7}{*}{ Plastics (max. 30\%) ${ }^{a}$} & Polyethylene & 9.9 & - & - & - & 16 & & \\
\hline & Polypropylene & 4.8 & & & & & & \\
\hline & Polyesters & 4.8 & & & & & & \\
\hline & Epoxies & 4.8 & & & & & & \\
\hline & Polyvinyl-chloride & 2.4 & & & & & & \\
\hline & Polytetra-flouroethane & 2.4 & & & & & & \\
\hline & Nylon & 0.9 & & & & & & \\
\hline
\end{tabular}

a Shuey et al., 2006 from Sum, 1991.

b Zhao et al., 2004.

c Zhang and Forssberg, 1997.

d Kim et al., 2004.

e Incinerated PCB Product.

${ }^{f}$ Iji and Yokoyama, 1997.

g Kogan, 2006.

h ICP-OES analysis of cell phone PCBs with hot aqua regia digestion.

compromise due to entrainment, which can also be promoted by kinetics (such as by carry over with water for fine particles, particle morphology enhanced drag, and upward mass transfer under turbulence). Grade versus recovery analysis of target constituent under the varying kinetics will therefore be a good indicator for assessing a favorable regime. This translates to optimizing metallic enrichment with recovery to the sink under varying kinetic regimes. List of factors contributing to kinetics of particle removal by bubbles in a flotation cell include gas flow rate, bubble diameter, cell volume, turbulence dissipation energy, fluid and particle densities, kinematic viscosity, efficiency of collection (which consist of efficiency of collision, attachment, and stability subprocesses), and of course quantity of the particles to be removed that are present at a time (Pyke et al., 2003). Though many, they are not all mutually exclusive variables, so that not all these need to be varied to observe the projected response. This paper reports the first phase of investigations into the prospects.

\section{Methodology}

\subsection{Sample generation}

Large assortment of populated eol PCBs, about $250 \mathrm{~kg}$ in all, from PCs, cell phones and switchboards were obtained. The PC boards mostly spanned 1989-2002, PI-PIV, Cyrix, Intel Celeron, IBM, Octek, Sockets 3, 7, 8. Most of the boards are multilayer (with maximum of 4-layers), with few older single sided types. All batteries and electrolytic capacitors bigger than one centimeter in diameter and height were manually removed. The boards were cut with a bench guillotine into roughly $4 \times 6 \mathrm{~cm}$ fragments appropriate for the choke of the swing hammer mill used (Eriez magnetics MACSA Pedestal Type Model 300). The size reduction was stage wise, starting from $20 \mathrm{~mm}$ closed fine crushing. Product from this stage was screen classified, and the $-13,200+1180 \mu \mathrm{m}$ frac- tion was removed from the stream being more of liberated metallic and plastic pieces amenable to eddy current separation, gravity air classifier, magnetic separation, etc. The $+13,200 \mu \mathrm{m}$ fraction containing almost bare PCBs fragments go through closed comminution again at 8,5 , and $2 \mathrm{~mm}$ screens to liberate copper traces, solders still locked in the board vias, pin insertions, board fibers, resins, etc. The $-1180 \mu \mathrm{m}$ fraction from the first stage was mixed with the final product from the $2 \mathrm{~mm}$ grinding stage.

The $-75 \mu \mathrm{m}$ fraction was screened from the final $-2 \mathrm{~mm}$ fraction. This material gave about $65 \%$ passing $-38 \mu \mathrm{m}$, and a loose packing density of $0.54 \mathrm{~g} / \mathrm{cm}^{3}$. Degree of liberation by point counting on scanning electron microscope (backscattered electron) images of polished sections of the sample gave $99.45 \%$. This is as good as complete liberation in conventional minerals processing, but can be significant with this sample where concentrations of target constituents range from ppm to percentages. The SEM images also show very diverse particle morphology. Detailed chemical composition and liberation characterization of the fines sample and issues peculiar to its flotation investigation are presented elsewhere (Ogunniyi et al., submitted for publication). Total sample obtained were split in to subsamples of about $5 \mathrm{~kg}$ and $500 \mathrm{~g}$. The sample was assayed via inductively coupled plasmaoptical emission spectroscopy (ICP-OES), and the assays were averaged with reconstituted assays from all the float fractions (Section 2.3).

\subsection{Flotation investigation}

A 3.51 Leeds cell (supplied by University of Cape Town) was used for experimental reproducibility. The kinetic parameters of interest were narrowed to air flow rate, impeller speed and pulp density. The interaction of these factors also varies other factors such as bubble sizes, pulp viscosity, and turbulent dissipation energy. Using distilled water, pulps containing 300 and 600 g sample 
Table 2

Designations of experimental conditions.

\begin{tabular}{llcl}
\hline Designation & Solid concentration, $\mathrm{v} / \mathrm{v} \%$ & Aeration, $\mathrm{ml} / \mathrm{min}$ & Agitation speed, $\mathrm{rpm}$ \\
\hline E11A & 32 & 500 & 300 \\
E21A & 16 & 500 & 300 \\
E21B & 16 & 500 & 400 \\
E21C & 16 & 500 & 500 \\
E22A & 16 & 1000 & 300 \\
E22B & 16 & 1000 & 400 \\
E22C & 16 & 1000 & 500 \\
\hline
\end{tabular}

were prepared per batch of flotation. This gives a pulp density of about 9 and 18 wt.\% corresponding to $16 \%$ and $32 \%$ solid concentration, respectively. As projected, no collector was used. It also turned out that no frother was needed (see section 3.1). Air flow rates were varied over 500 and $1000 \mathrm{ml} / \mathrm{min}$, and agitations over 300,400 and $500 \mathrm{rpm}$ impeller speeds for the $300 \mathrm{~g}$ pulp. Only one condition was experimented for the $600 \mathrm{~g}$ pulp due to experimental observations (see section 3.2). Designations of the combinations of experimental conditions are summarized in Table 2. Compared with natural mineral investigations with values such as $1200 \mathrm{rpm}$ impeller speed and 1.8-5.4 1/min and higher aeration (Forrest et al., 2001; Lins and Adamian, 1993; Miller et al., 2006), the low regimes chosen for these parameters is based on initial microflotation and the Leeds cell exploratory trials. Above the range of $500 \mathrm{rpm}$ agitation and $1000 \mathrm{ml} / \mathrm{min}$ aeration, the turbulence reached the pulp surface. Each experimental condition was run in duplicate and mass pulls at $1,4,10,18$, and 30 min were collected. The natural pulp $\mathrm{pH}$ was measured in 12 pulps, for record. The resulting float and sink fractions were oven dried, and weighed. All the mass pulls were confirmed to repeat within 5$10 \%$.

\subsection{Analysis}

The concentrate mass percent (fraction of the feed remaining in the sink) was calculated as an inverse indication of the ratio of concentration for the reverse flotation. For a first check of the conformity of the response to flotation behavior, the cumulative mass fraction recovered to float for all conditions was fitted to the classical first order kinetics model in the form (Kelly and Spottiswood, 1989; Polat and Chander, 2000):

$\ln \mathrm{Rm} /(\mathrm{Rm}-R)=k t$

where $\mathrm{Rm}$ is the maximum cumulative recovery, $k$ is the rate constant, and $R$ is recovery at time, $t$. Samples of the fractions were digested in hot aqua regia among other possible digestion routes (following recommendation in Ogunniyi et al., submitted for publication), and undigested residue filtered and weighed. A quick assessment of the enrichment of metallic values into the sink was first done using the fractions of each sink sample digested as an indication of total metallic assay. Indication of recoveries was also computed based on this. Assays of selected elements were analyzed from the leach solutions with ICP-OES, for a better indication of the deportments in respect of the elements, specifically $\mathrm{Ag}, \mathrm{Al}, \mathrm{Au}, \mathrm{Ca}$, $\mathrm{Cu}, \mathrm{Fe}, \mathrm{Mg}, \mathrm{Ni}, \mathrm{Pb}, \mathrm{Pd}, \mathrm{Pt}, \mathrm{Si}, \mathrm{Sn}, \mathrm{Ti}$, and Zn. Elemental assays, enrichment ratios (ratio of concentrate to feed assay) and recoveries, over time into sink were computed from these data.

\section{Result and discussion}

\subsection{Natural hydrophobic response}

Without addition of any reagent, the pulp pH averaged 8.00 $(\delta r=1.6 \%)$. For all the kinetic conditions investigated, and without any frother addition, stable froths formed in the cell (Fig. 1). This distinctly shows that the natural hydrophobic response exists. The ensuing question then is the origin of this froth. A possible assumption is for an inherent frothing constituent in the heterogeneous sample. Exploring this, an inventory of organics present in the sample will show that none of the thermoplastic constituents, PVC, PE, PPE, PTFE, etc. (Table 1) are water soluble. Considering the flame retardant additives in the resins, most congeners in this broad class are reported as not water soluble (D'Silva, 2004). However, tetrabromobisphenol-A (TBBPA), which is a principal epoxy resin used in PCBs, is reported to show low water solubility, thus making the analysis more interesting. Froth stability tests using a Betachem modified Bikerman test rig (Betachem, SA) with a pulp of the sample (at same solid concentration as investigated) gave dynamic froth stability height of $5 \mathrm{~cm}$, while filtrate from the pulp (of the same solid concentration) gave no stable froth to measure. This basically shows that the observed frothing is strongly due to something else, and not a soluble heteropolar organic compound. This is further substantiated by the fact that the actual solubility of the suspect compound (TBBPA) is $0.148 \mathrm{mg} / \mathrm{l}$ (Chemtura, 2005), a value about one-hundredth of typical surfactants dosages (Crozier and Klimpel, 1989). Pendant drop surface tension measurement of the pulp filtrate also gave averages around 72 dynes/ $\mathrm{cm}$ as for deionised water, and higher precision (such as capillary rise) measurement was considered unnecessary.

Another possibility is that this froth results from fine particle stabilization. In this connection, it may be necessary to first address the frothing phenomena a bit broadly. Froth is formed on aerating a solution or a suspension if trapping of air (or gas) bubbles by the liquid film could be achieved. Froth is therefore a dispersed system, and in essence unstable: it will want to break down spontaneously to lower overall surface and energy (Harris, 1982). Stability of the froth film is therefore the major issue in achieving a tangible froth.

With surfactant solutions, overall surface tension is lower, so also is the free energy difference accompanying surface reduction. This reduces the spontaneity of breakdown, giving a metastable two-phase froth. In pulps of surfactant solution (as in mineral processing), it is recognized that the stability of the three-phase froth is increased or decreased by solid particles in pulp, with particle size, shape and degree of hydrophobicity as the interacting factors (Klassen and Mokrousov, 1963; Harris, 1982; Feng and Aldrich, 1999; Pease et al., 2005). With particles of low hydrophobicity, froth film stabilization occurs when a closed packed monolayer of particles is formed in the froth film (Harris, 1982). In this case, the particles which are attached to the interfaces cannot be forced

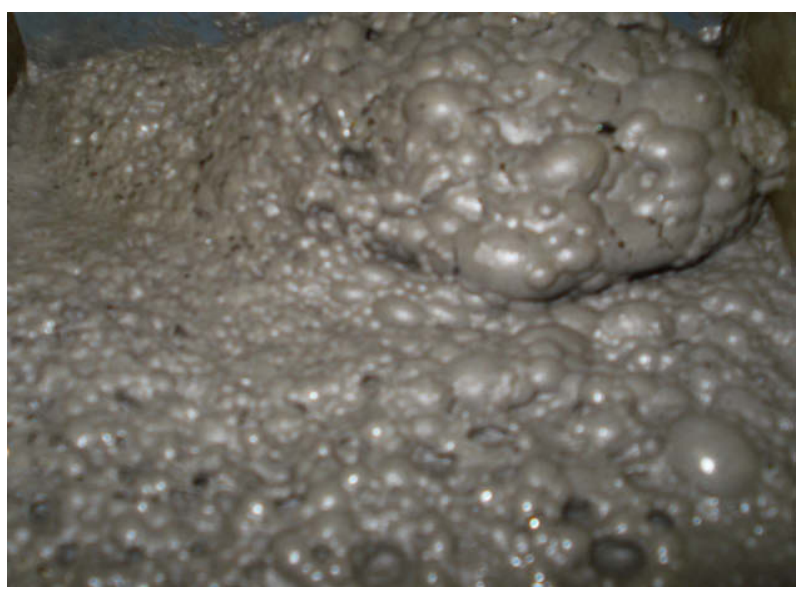

Fig. 1. $\mathrm{PCB} C \mathrm{CF}$ froth in the flotation cell under natural hydrophobic response. 
out of the film and the two interfaces are kept apart. Flocculation of particles also prevent coalescence of bubbles in the froth (Harris, 1982), the film wall being sort of reinforced. The other extreme which also obtains is stability of froth solely by fine particles in surfactant free pulps. Molecular solutions of compounds such as diacetone alcohol and ethyl acetal (compounds that do not alter solutions surface tension) have been shown to produce adequate froth with fine coal (hydrophobic) particles (Lekki and Laskowski, 1975). Three-phase froth has also been generated by aerating a suspension of clean hydrophilic nanosized silica particles in distilled water (Bindal et al., 2002). It was submitted that the foaminess observed was directly proportional to particle concentration and inversely proportional to particle size, and the self organization of the colloidal particles in to layered structure between gas bubbles provided a barrier against coalescence of bubbles, thereby stabilizing the foam lamella (Bindal et al., 2002). All this is to submit that, in two-phase froth, lowering of surface tension is a prerequisite, while this is not compulsory to achieve a tangible threephase froth; fine particle stabilization will suffice. Hydrophilic and hydrophobic particles have been observed to stabilize froth; appropriate size is what matters.

From this standpoint, it is easy to see possibility of the observed froth resulting from fine particles stabilization. The sample contains about $65 \%$ passing $38 \mu \mathrm{m}$, with bulk of this from the brittle glass fiber and thermoset (epoxy resin) constituents. Close packing of particles in the froth lamella as well as flocculation of particles (as suggested by thick bubble interstices seen in the froth) are two major mechanisms that can be inferred for stabilization of the froth. This view will partly explain the generally high mass pulls also observed. At above $50 \%$ in most cases (Fig. 2), it follows that the response is not due to the projected natural hydrophobicity of some particles alone. Strands of copper particles from the PCB traces could be found in the float fraction, while glass fibers abound. A first rationale to this is entrainment enhanced by the elongated morphology. Secondly, it will be recalled that in PCB production, the fibers were impregnated with the resin until it sets in place on the fiber. Strong adhesion between the reinforcement and the matrix is a quality requirement in composites. Flotation due to air bubble attachment to the resin impregnated pseudo hydrophobic surface can therefore be another strong reason for the glass fibers transport to the froth. With the high proportion of these fibers in the sample, recovery to froth of other particles by water as well as entrainment under the bulk upward mass transfer became pronounced. The various kinetic regimes will be

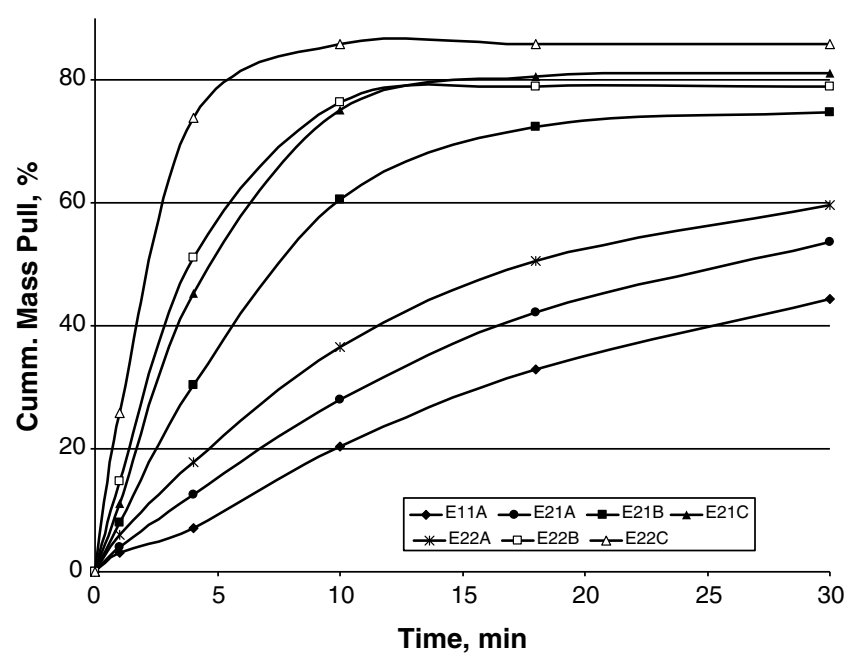

Fig. 2. Cumulative mass pull with time under natural hydrophobic response and varying kinetic parameters. expected to promote this differently, and this can reflect in how well the responses under each regime fit to the first order kinetics.

\subsection{Kinetic response}

Fig. 2 shows the cumulative mass pull with time under varying kinetic regimes. The E11A condition shows that at the $32 \%$ solid concentration, the proportion of froth-phase bound particles in the cell appears too high such that mass pull did not stabilize with time even after $30 \mathrm{~min}$. Driving the rate higher with higher hydrodynamics will simply worsen entrainment and grossly compromise selectivity. The high proportion of the glass fiber particles and its tendency to increase viscosity will also aid these. Subsequent runs were therefore at the lower solid concentration. With increasing combinations of the kinetic parameters, the mass pull rate can be seen to increase until the mass recovery curves show definite asymptotes at the experimental conditions of E21C, E22B and E22C. As mentioned before (Section 2.2), it is notable that this prevailing kinetics, which suffice to keep the particle in suspension, corresponds to impeller energy and aeration rate much lower than what obtains in conventional minerals flotation; the sample being of much lower aggregate density.

The extents of fit of the responses to Eq. (1) can be seen in Fig. 3. All the conditions gave good correlation, indicating that the observed response conforms to describable froth flotation phenomena. It is notable that E21C and E22B gave competing performance base on rate constant, correlation coefficient, and cumulative mass pull (Figs. 2 and 3), and this can be an indication of possible optimizing trends. However, the reverse enrichment of the desired metallic values into the sinks will give clear basis for assessing the performance of the scheme.

\subsection{Sink enrichment: digested total metallic content}

Fig. 4 summarizes sinks enrichment based on the fractional digestion data. The general trend shows assay-recovery tradeoff, typical of beneficiation operations. The low enrichments (assays) indicated for E11A and E21A confirms the inadequate pulp density and kinetics noted for these conditions. Highest recovery in E11A merely indicates that the bulk of the feed (55\% concentrate mass) still remains in the sink; $100 \%$ recovery can as well be achieved by carrying out no beneficiation. E22C gave indication of the best assay as $43 \%$, but with the worst compromise on recovery. E21C and E22B with best performances based on kinetic assessment, also appear to give the best combinations of assay and recovery, with $42 \%$ and $38 \%$ assays and recoveries of $39 \%$ and $41 \%$, respectively.

As these responses are based on the natural hydrophobic response, with no collector or frother, no treatment to alter hydro-

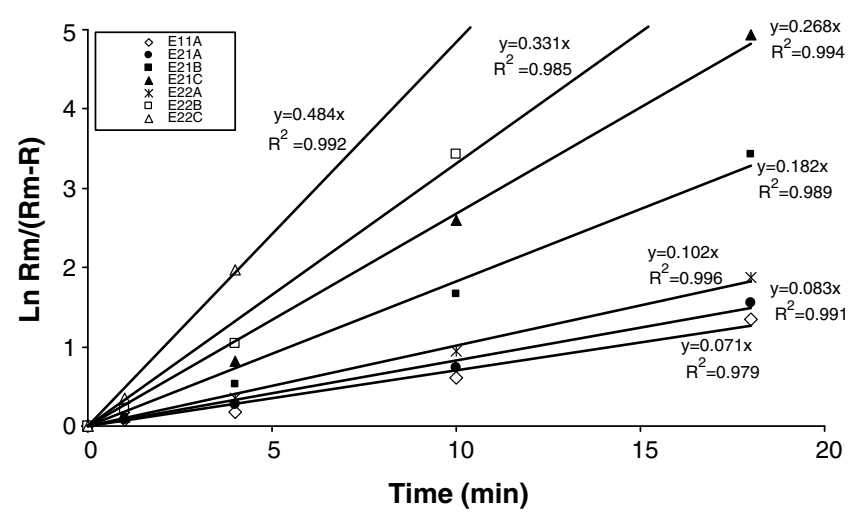

Fig. 3. First order fitting of the responses under various kinetic conditions 


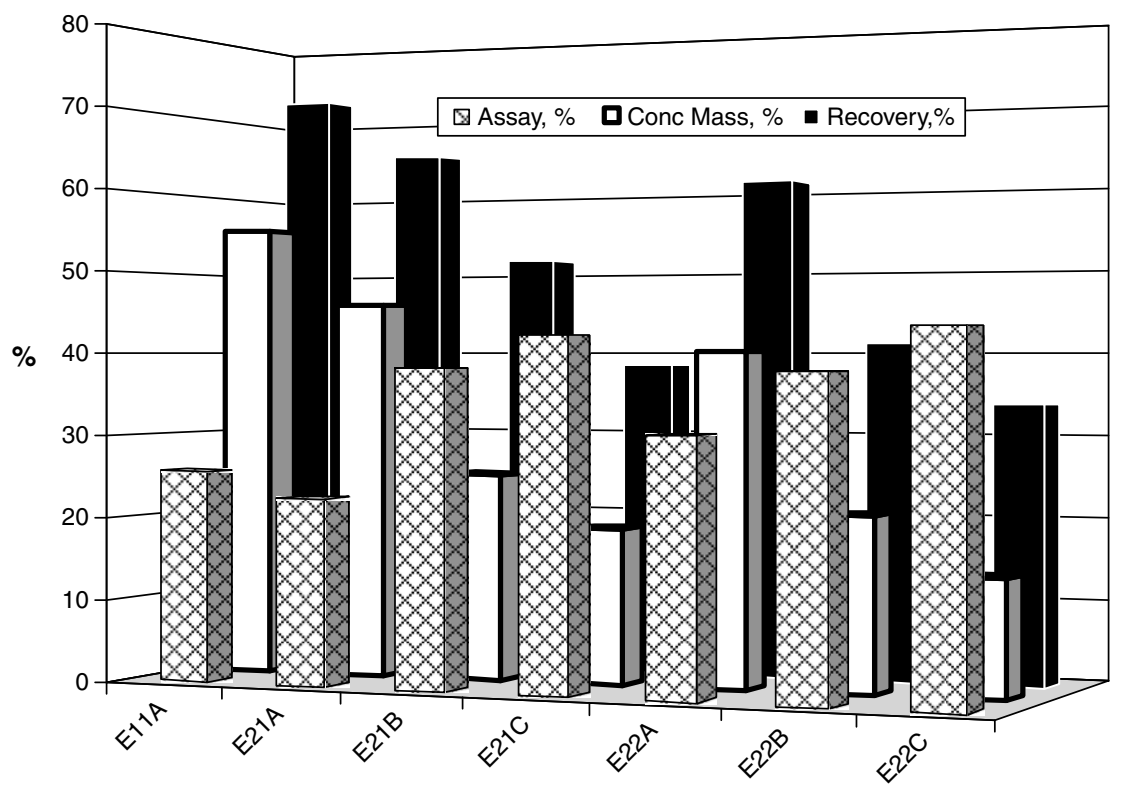

Fig. 4. Indications of enrichment of metallic values into the sinks.

phobicity, the responses must be explained from the kinetic parameters variation. From the flotation cell operation, higher impeller speeds, at constant aeration, produce finer bubbles. Finer bubbles imply higher bubble surface area, lower buoyancy and increased residence time. Increased turbulent dissipation energy is also a direct effect of higher impeller speed. These will increase particle-bubble collision probability (Duan et al., 2003; Pyke et al., 2003), which is precursor to attachment. Smaller bubbles also improve fines recovery to float (Pease et al., 2005). To the extreme, this condition (increasing turbulence) can also increase entrainment at the expense of the reverse recovery. Hence, higher mass pull (lower sink concentrate mass) was observed from increasing impeller speeds, as can be seen in Figs. 2 and 4, comparing E22A, E22B and E22C, or E21A, E21B and E21C. With this trend, lower concentrate mass resulted in lower reverse recovery, implying target value loss to the high mass pull. Conversely, assay increased with lower concentrate mass and lower reverse recovery as more froth-phase particle could go up at the higher mass pull leaving a smaller but richer sink.

The performance across the category can also be resolved on this basis. Comparing E21C and E22B, the result reflects the interplay of superficial gas velocity and the superficial surface area rate of bubbles on recovery and rate. The higher buoyancy of the larger bubbles (at the lower speed) of E22B, and the larger flow rate reflects in the higher rate constant. But with lower residence time of the much larger bubbles, particle-bubble collision probability became lower after substantial mass is pulled, thus ending mass pull around $12 \mathrm{~min}$ (Fig. 2). E21C, on the other hand, with half aeration rate showed slower rate, but the higher residence time of the finer bubbles (at higher impeller speed) is able to compensate for half air flow rate and achieve overall higher mass pull over time compared to E22B. This condition in E21C also allowed for a little more mass pull even after $18 \mathrm{~min}$. However, this extra pull turns out a disadvantage based on the elemental analysis of sink enrichment with time.

\subsection{Sink enrichment: elemental analysis}

Table 3 shows reconstituted feed assays of selected elements from the float and sink fractions for all the runs, averaged with that of direct feed sample: this is a total of 14 assays averaged for each element. Table 4 summarizes the recoveries and enrichment ratios of specific elements for all the sinks, while separate plots of the enrichment ratio (ER) versus reverse recovery in the sinks with time for some selected elements under the different kinetics are shown in Figs. 5-10. Enrichment ratio has been used to give uniform basis for comparison as the assays range from ppm to percentages for the different elements. Also, with the assay scale, a response can lie above another even at $t=0$ (that is, before any enrichment), due to feed sample assay variations in such heterogeneous stock. Feed sample assays for gold, for instance, in this analysis range from 190 to 219 ppm, while Pd was 160-165 ppm.

First considering the response of gold, the best recovery of $79 \%$ was obtained at the lowest ER of 1.72, under the conditions of E12A, while the best ER of 3.65 was achieved with a recovery of $51 \%$, under E22C experimental condition (Table 4). A combination of $64 \%$ recovery and 3.05 ER which appears to be an optimum was obtained under E22B condition. This is a better performance compared to E21C which gave a recovery of $58 \%$ at almost the same ER of 3.08. This is actual assay of $626 \mathrm{ppm}$ at 58\% recovery in E21C, with equivalent of $622 \mathrm{ppm}$ at $64 \%$ recovery for E22B. Trading off such little enrichment for $6 \%$ higher recovery is a good economic judgment with metals like gold. The picture is clear in Fig. 5 show-

Table 3

Feed assay of select elements.

\begin{tabular}{lll}
\hline Element & Average assay (\%) & Relative std. dev. (\%) \\
\hline $\mathrm{Ag}$ & 0.0662 & 19.99 \\
$\mathrm{Al}$ & 3.4864 & 0.81 \\
$\mathrm{Au}$ & 0.0202 & 5.68 \\
$\mathrm{Ca}$ & 7.0078 & 2.92 \\
$\mathrm{Cu}$ & 3.6783 & 2.63 \\
$\mathrm{Fe}$ & 2.7656 & 1.20 \\
$\mathrm{Mg}$ & 0.2001 & 1.88 \\
$\mathrm{Ni}$ & 0.2195 & 2.85 \\
$\mathrm{~Pb}$ & 2.6007 & 1.19 \\
$\mathrm{Pd}$ & 0.0162 & 1.64 \\
$\mathrm{Pt}$ & 0.0002 & 100.8 \\
$\mathrm{Si}$ & 0.0280 & 12.79 \\
$\mathrm{Sn}$ & 3.6855 & 2.25 \\
$\mathrm{Ti}$ & 0.2748 & 2.38 \\
$\mathrm{~V}$ & 0.0033 & 2.14 \\
$\mathrm{Zn}$ & 0.5975 & 3.77 \\
\hline
\end{tabular}


Table 4

Recoveries (Rec) and enrichment ratios (ER) for specific elements in the sinks.

\begin{tabular}{|c|c|c|c|c|c|c|c|c|c|c|c|c|}
\hline \multirow[t]{2}{*}{ Elements } & \multicolumn{2}{|l|}{ E21A } & \multicolumn{2}{|l|}{ E21B } & \multicolumn{2}{|l|}{ E21C } & \multicolumn{2}{|l|}{ E22A } & \multicolumn{2}{|l|}{ E22B } & \multicolumn{2}{|l|}{ E22C } \\
\hline & Rec, \% & ER & Rec, \% & ER & Rec, \% & ER & Rec, \% & ER & Rec, \% & ER & Rec, \% & ER \\
\hline $\mathrm{Ag}$ & 42 & 0.93 & 24 & 0.80 & 19 & 1.04 & 32 & 0.79 & 18 & 0.87 & 17 & 1.18 \\
\hline $\mathrm{Al}$ & 46 & 0.99 & 22 & 0.74 & 16 & 0.83 & 39 & 0.96 & 18 & 0.88 & 12 & 0.88 \\
\hline $\mathrm{Au}$ & 79 & 1.72 & 68 & 2.52 & 58 & 3.08 & 77 & 1.90 & 64 & 3.05 & 51 & 3.65 \\
\hline $\mathrm{Ca}$ & 42 & 0.92 & 19 & 0.63 & 12 & 0.66 & 35 & 0.87 & 15 & 0.72 & 10 & 0.67 \\
\hline $\mathrm{Cu}$ & 66 & 1.44 & 47 & 1.70 & 38 & 2.04 & 61 & 1.53 & 41 & 1.93 & 31 & 2.21 \\
\hline $\mathrm{Fe}$ & 61 & 1.35 & 42 & 1.51 & 33 & 1.76 & 56 & 1.38 & 35 & 1.65 & 27 & 1.93 \\
\hline $\mathrm{Mg}$ & 45 & 0.98 & 23 & 0.79 & 17 & 0.90 & 39 & 0.96 & 20 & 0.93 & 14 & 1.02 \\
\hline $\mathrm{Ni}$ & 76 & 1.65 & 60 & 2.21 & 50 & 2.66 & 72 & 1.78 & 54 & 2.56 & 42 & 2.97 \\
\hline $\mathrm{Pb}$ & 74 & 1.60 & 55 & 2.02 & 45 & 2.37 & 67 & 1.68 & 46 & 2.20 & 34 & 2.40 \\
\hline Pd & 80 & 1.74 & 64 & 2.37 & 52 & 2.74 & 77 & 1.91 & 58 & 2.76 & 46 & 3.23 \\
\hline $\mathrm{Si}$ & 37 & 0.82 & 27 & 0.93 & 30 & 1.57 & 45 & 1.11 & 31 & 1.47 & 32 & 2.23 \\
\hline Sn & 70 & 1.53 & 51 & 1.84 & 40 & 2.12 & 64 & 1.58 & 42 & 1.98 & 30 & 2.09 \\
\hline $\mathrm{Ti}$ & 81 & 1.77 & 72 & 2.70 & 66 & 3.52 & 79 & 1.96 & 67 & 3.21 & 61 & 4.31 \\
\hline $\mathrm{Zn}$ & 73 & 1.58 & 56 & 2.05 & 47 & 2.50 & 68 & 1.70 & 51 & 2.44 & 43 & 3.05 \\
\hline
\end{tabular}

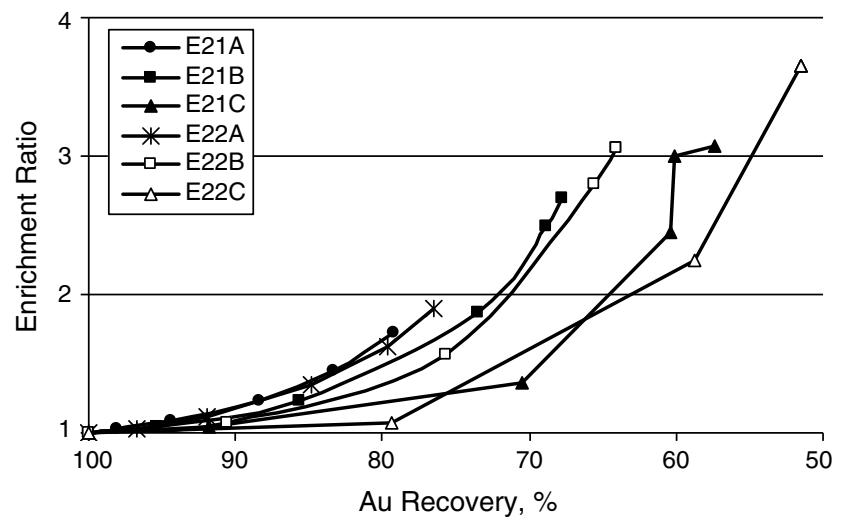

Fig. 5. Enrichment ratio vs. recovery for Au in sinks under varying kinetic regime.

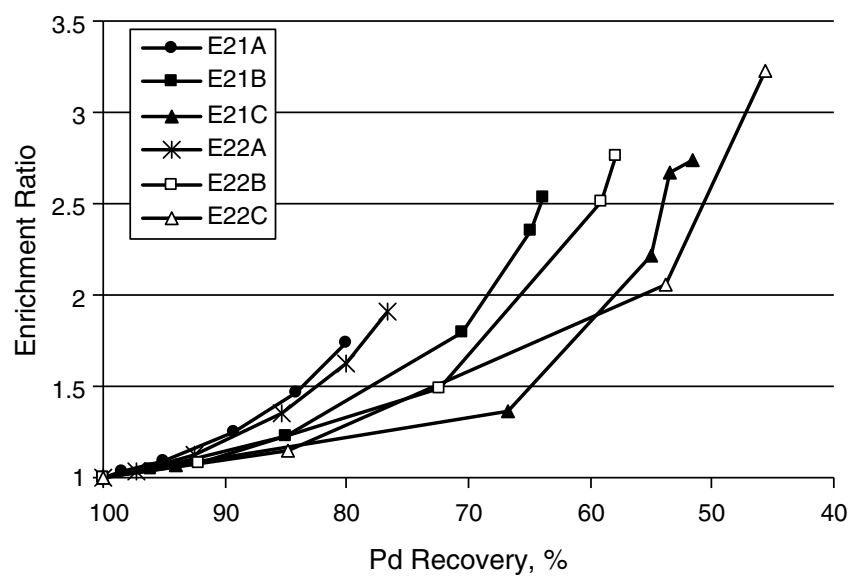

Fig. 6. Enrichment ratio vs. recovery for Pd in sinks under varying kinetic regime.

ing the E22B plot lying well ahead (higher recovery) that of E21C. For palladium, E22B plot (Fig. 6) also lies clearly ahead and above (higher enrichment) that of E21C showing glaring better performance; the final assay and recovery being $456 \mathrm{ppm}$ at $58 \%$ for E22B. Ni and $\mathrm{Zn}$ are other elements for which E22B can be taken as giving best performances (Table 4), with actual assays of $5562 \mathrm{ppm}$ and $1.43 \%$, respectively.

For $\mathrm{Ti}$ and $\mathrm{Pb}$, a careful observation of the responses in Figs. 7 and 8 shows that E21C gave better performance over E22B. Before 18 min, E22B mass pull has stopped (Fig. 2), while E12C still con-

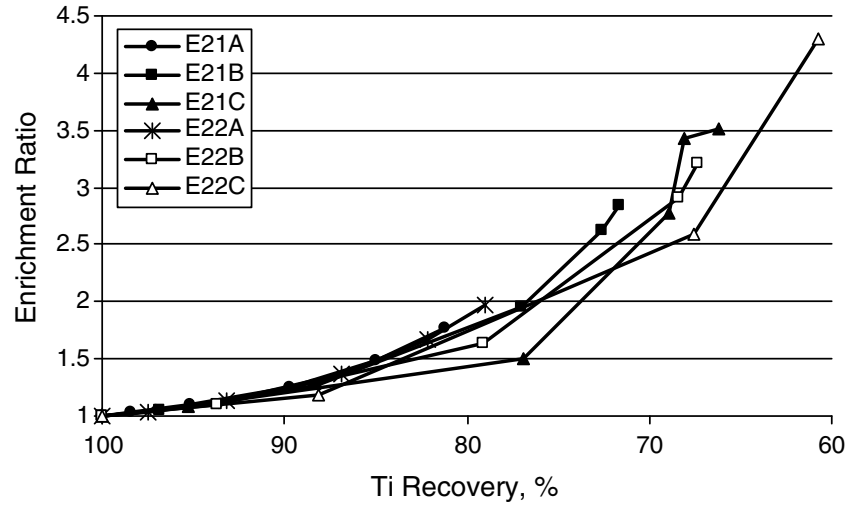

Fig. 7. Enrichment ratio vs. recovery for Ti in sinks under varying kinetic regime.

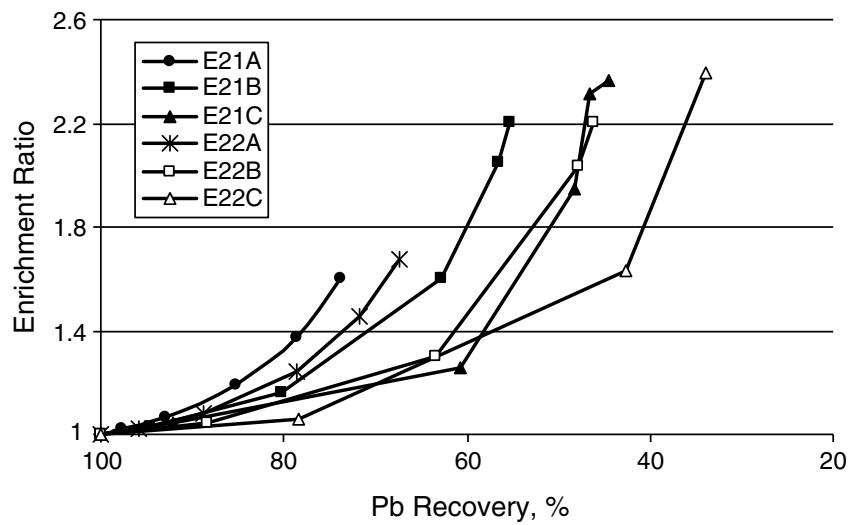

Fig. 8. Enrichment ratio vs. recovery for $\mathrm{Pb}$ in sinks under varying kinetic regime.

tinued with little pull until the 30th minute of flotation. In this last interval, a disproportionate drop in recovery versus ER in all the E21C plots in Figs. 5-9 can be observed. Plots of $\mathrm{Sn}$ and $\mathrm{Cu}$ (not shown) also show the same trend. Comparing the two operating conditions at the end of $18 \mathrm{~min}, \mathrm{E} 21 \mathrm{C}$ gave better enrichment ratios and better or almost equal recoveries compared with E22B. It implies that E21C operating parameter need only run for $18 \mathrm{~min}$, as for E22B, to result in better ER and recovery for these elements.

The response for Fe (Fig. 9) also shows best performance under E21C, though with high compromise on recovery dropping down to $37 \%$ at $18 \mathrm{~min}$. With E22B and E22C condition, a worse perfor- 


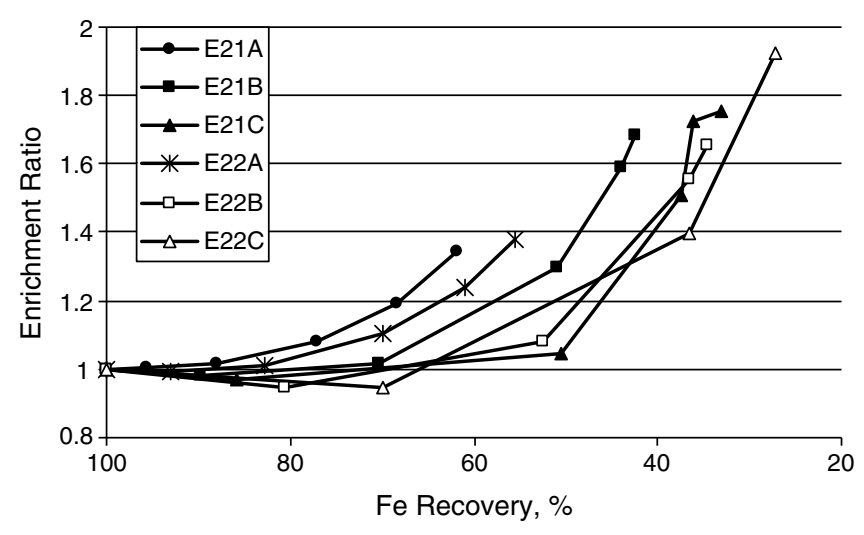

Fig. 9. Enrichment ratio vs. recovery for Fe in sinks under varying kinetic regime.

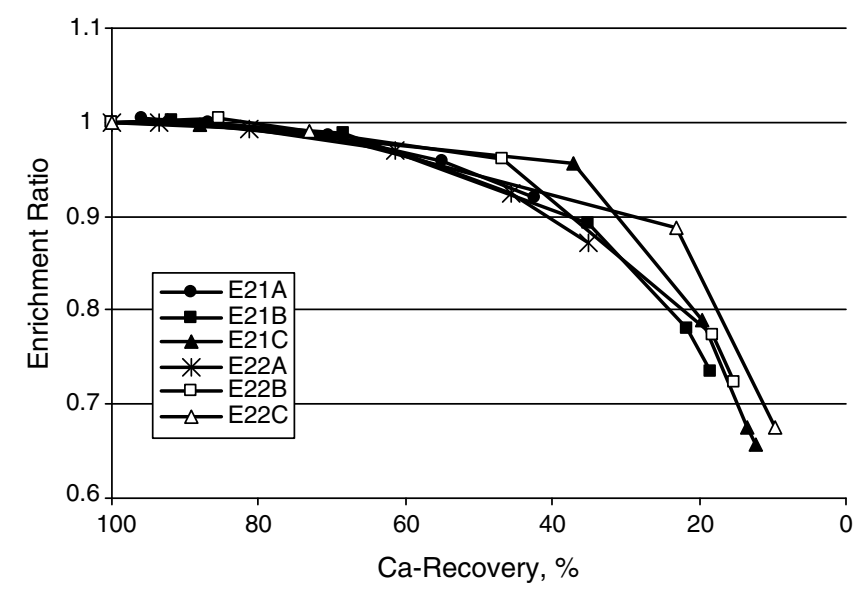

Fig. 10. Enrichment ratio vs. recovery for Ca in sinks under varying kinetic regime.

mance of negative enrichment could even be observed at some stage in the pulp. This negative enrichment is more pronounced with $\mathrm{Ag}, \mathrm{Mg}$, and $\mathrm{Al}$ (Table 4), showing that these elements prefer the froth phase. Recoveries dropped below $20 \%$ at ER of 0.9 under E21C for Mg, for instance. Ca is of special interest due to its significant proportion $\sim 7 \%$ in the feed (Table 3 ). Consistent reduction in the sinks' Ca assay (negative ER) over time for all the conditions can be seen in Fig. 10, giving less than 15\% residual recovery in the sink for E21C. Platinum assays were too low - a few ppm for reliable analytical figures (see relative standard deviation of Pt assay in Table 3).

Attempting to explain these responses, for metallic particles that reports to the sink, this is as expected. Metallic particles will have high surface energy, be hydrophilic (Gupta and Yan, 2006), and therefore prefer the sink. Density advantage is also expected here to enhance the separability between denser hydrophilic metallic particles and lighter hydrophobic plastic particles. The questions then will be why is recovery to sink not $100 \%$ for such metals, and why do some metallic elements preferentially report to the froth? It is necessary to appreciate that the elements are contained in particles occurring as some end-use alloy or compounds, these particles are present in very diverse shapes, and still can be part of a composite particle. The degree of liberation of 99.45\% estimated for the sample corresponds to more than $5000 \mathrm{ppm}$ of unliberated particle. Assuming 100 of these are from the approximately $200 \mathrm{ppm}$ gold constituents. Then the response of gold may no longer be expected to be total. Comminution of ductile metallic materials generally gives particles with very random shapes, including flattened pieces which will have tendency to float around in the pulp, particularly in this size range. Gold flakes float for this reason in conventional minerals flotation (Allan and Woodcock, 2001). The split of $\mathrm{Cu}$ to the float and sink stream is another example that can be readily attributed to shape influence. Copper particles from the PCB traces remain in elongated forms that can be easily entrained. Hence, short strands of the PCB copper trace were found in the float, as noted earlier (Section 3.1). On the other hand, those from copper nuts, edges, etc, which could have chipped into a more cubical particle, can resist the upward current and sink better.

For metals preferring the froth phase, probable reasons can also be the size and shape in which particles occur. For instance, $\mathrm{Al}, \mathrm{Ca}$, and $\mathrm{Mg}$ from the oxides (Table 1 ) will occur as very fine particles from comminution of the ceramics. The brittle ceramics would have undergone more selective pulverization relative to the ductile metallic alloys. The much finer particles can easily be entrained with water at the prevailing kinetics for the relatively larger metallic particles. It is expected that favorable kinetics will differ among particles in the whole $-75 \mu \mathrm{m}$ size range (Pease et al., 2005). On the other side, fine $\mathrm{Al}$ particles can also occur as flattened chip from the ductile alloy. Chances are that the flat or foil chips, coupled with low density of aluminum can be entrained under bulk upward mass transfer of the glass fibers. The same shape factor can be expected to influence $\mathrm{Mg}$, being even lighter than $\mathrm{Al}$.

From the foregoing, it follows that the interacting mechanisms that can be responsible for the responses observed include: the projected natural hydrophobic response to float and hydrophilic preference for the sink; presence of hydrophobic material on an otherwise hydrophilic surface; particle morphology enhanced entrainment; and fine particle entrained in water to froth. The kinetic regimes investigated were seen to promote these factors differently as the responses vary with kinetic conditions. To one extreme, recovery can be compromised, and to the other, enrichment. The actual range of values for the kinetic parameters to give the most favorable regime to optimize the performance will of course vary to some extent between cells (O'Connor et al., 1987). In the present observation, the favorable range is $400 \mathrm{rpm}$ impeller speed with $1000 \mathrm{ml} / \mathrm{min}$ aeration to $500 \mathrm{rpm}$ with $500 \mathrm{ml} / \mathrm{min}$ aeration. This gives a definite indication of the low (turbulence) energy requirement of this sample relative to conventional minerals flotation. The analysis also shows that the interactions of the various factors favor enrichments and recoveries of $\mathrm{Au}$ and Pd to the sink. The response from these precious metals, which are the economic drivers for $\mathrm{PCB}$ resource recovery, shows the scheme can indeed be prescribed for PCB comminution fines beneficiation. With the recovery values across the elements, it is notable that room for improvement should still exist on the performance from this scheme. With about 65\% passing $38 \mu \mathrm{m}$ in this sample and recognizing that the same kinetics regime can not favor all the particles in the $-75 \mu \mathrm{m}$ range (Pease et al., 2005), a narrower size distribution over separate kinetic regime is probable for better performance.

\section{Conclusions}

A novel application of froth flotation for beneficiation of PCB CF has been investigated. Response under natural hydrophobic condition was projected to differ among the assorted particles in the sample, and this was exploited by a kind of reverse flotation. The response was found to exist, and enrichment versus recovery to the sink could be optimized with variation in the operating kinetic regimes. Au and Pd, which are the major economic drivers of PCB processing, were among the elements best enriched into the sink. The results provide a basis to consider froth flotation as applicable for PCB CF beneficiation, and the natural hydrophobic response 
scheme effective in this connection. Performance improvement looks feasible and more study on the response observed also interesting.

\section{References}

Allan, G.C., Woodcock, J.T., 2001. A review of the flotation of native gold and electrum. Minerals Engineering 14 (9), 931-962.

Alter, H., 2005. The recovery of plastics from waste with reference to froth flotation. Resources, Conservation and Recycling 43, 119-132.

Araujo, A.C., Viana, P.R.M., Peres, A.E.C., 2005. Reagents in iron ore flotation. Minerals Engineering 18, 219-224.

Arnold, B.J., Aplan, F.F., 1989. The hydrophobicity of coal macerals. Fuel 68, 651658.

Betachem (Pty) Ltd., Johannesburg 2195, South Africa. Available from: <www.bchem.co.za>.

Bindal, S.K., Sethumadhavan, G., Nikolov, A.D., Wasan, D.T., 2002. Foaming mechanisms in surfactant free particle suspensions. AIChE Journal 48 (10), 2307-2314.

Chemtura Product Safety Group, 2005. Material safety data sheet, \# 00016. Product name: Great Lakes BA59P ${ }^{\mathrm{m}}$ and BA-59PC ${ }^{\mathrm{m}}$. Chemtura USA Corporation.

Crozier, R.D., Klimpel, R.R., 1989. Frothers: plant practices. Minerals Processing and Extractive Metallurgy Review 5, 257-279.

Dodbiba, G., Haruki, N., Shibayam, A., Miyazaki, T., Fujita, T., 2002. Combination of sink-float separation and flotation technique for purification of shredded PETbottle from PE or PP flakes. International Journal of Mineral Processing 65, 1129.

D'Silva, K., 2004. Brominated organic micropollutants - igniting the flame retardants issue. Critical Reviews in Environmental Science and Technology 34, 141-207.

Duan, J., Fornasiero, D., Ralston, J., 2003. Calculation of the flotation rate constant of chalcopyrite particles in an ore. International Journal of Mineral Processing 72, 227-237.

Feng, D., Aldrich, C., 1999. Effect of particle size on flotation performance of complex sulphide ores. Minerals Engineering 12 (7), 721-731.

Forrest, K., Yan, D., Dunne, R., 2001. Optimization of gold recovery by selective gold flotation for copper gold-pyrite ores. Minerals Engineering 14 (2), 227-241.

Goosey, M., Kellner, R., 2002. A Scoping Study: End-of-life Printed Circuit Boards. Department of Trade and Investment, Shipley Europe Limited.

Gupta, A., Yan, D.S., 2006. Minerals Processing Design and Operation: An Introduction. Elsevier (Chapter 16).

Harris, P.J., 1982. Frothing phenomena and frother. In: King, R.P. (Ed.), Principles of Flotation. SAIMM, Johannesburg, pp. 17-30.

Iji, M., Yokoyama, S., 1997. Recycling of printed wiring boards with mounted electronic components. Circuit World 23 (3), 10-15.
Kelly, G.E., Spottiswood, D.J., 1989. Introduction to Mineral Processing. John Willey \& Sons, Australia.

Kim, B., Lee, J., Seo, S., Park, Y., Sohn, H., 2004. A process for extracting precious metals from spent printed circuit boards and automobile catalysts. JOM 56 (12), 55-58.

Klassen, V.I., Mokrousov, V.A., 1963. An Introduction to the Theory of Flotation. Butterworth, London.

Kogan, V., 2006. Process for the recovery of precious metals scrap by means of hydrometallurgical technique. Patent Application. WO 6006/013568 A3.

Lekki, K., Laskowski, J., 1975. A new concept of frothing in flotation system and general classification of flotation frothers. In: Proceedings of 11 th International Minerals Processing Congress, Cagliari. pp. 427-448.

Lins, F.F., Adamian, R., 1993. The influence of some physical variables on gold flotation. Minerals Engineering 6 (3), 67-277.

Miller, J.D., Kappes, R., Simmons, G.L., LeVier, K.M., 2006. Pyrite activation in amy xanthate flotation with nitrogen. Mineral Engineering 19 (6-8), 659-665.

O'Connor, C.T., Dunne, R.C., Duncan, R.B., 1987. Comparison of performance of various laboratory flotation cells. Transactions of the Institution of Mining and Metallurgy Section C 96, 168-170.

Ogunniyi, I.O., Vermaak, M.K.G., 2007. Improving printed circuit board physical processing - an overview. In: Proceedings of European Metallurgical Conference. Dusseldorf, Germany, pp. 1645-1656.

Ogunniyi, I.O., Vermaak, M.K.G., in press. Froth flotation for beneficiation of printed circuit board comminution fines: an overview. Mineral Processing and Extractive Metallurgy Review.

Ogunniyi, I.O., Vermaak, M.K.G., Groot, D.R., submitted for publication. Chemical composition and liberation characterization of printed circuit board comminution fines for beneficiation investigations. Waste Management.

Pease, J.D., Curry, D.C., Young, M.F., 2005. Designing flotation circuits for high fines recovery. In: Centenary of Flotation Symposium, Brisbane, QLD, June 6-9. pp. 905-912.

Polat, M., Chander, S., 2000. First order flotation kinetics models and methods for estimation of the true distribution of flotation rate constants. International Journal of Mineral Processing 58, 145-166.

Pyke, B., Fornasiero, D., Ralston, J., 2003. Bubble particle heterocoagulation under turbulent conditions. Journal of Colloid and Interface Science 265, 141-151.

Saitoh, K., Nagano, I., Izumi, S., 1976. New separation technique for waste plastic. Resource Recovery and Conservation 2, 127-145.

Shent, H., Pugh, R.J., Forssberg, E., 1999. A review of plastics waste recycling and the flotation of plastics. Resources, Conservation and Recycling 25, 85-109.

Shuey, S.A., Vildal, E.E., Taylor, P.R., 2006. Pyrometallurgical processing of electronic waste. In: SME Annual Meeting, St. Louis, MO, March 27-29. Preprint 06-037.

Sum, E.Y.L., 1991. The recovery of metals from electronic scrap. JOM (April), 53-60.

Zhang, S., Forssberg, E., 1997. Mechanical separation-oriented characterization of electronic scrap. Resource, Conservation and Recycling 21, 247-269.

Zhao, Y., Wen, X., Li, B., Tao, D., 2004. Recovery of Copper from printed circuit boards. Minerals and Metallurgical Processing $21(2), 99-102$. 